\section{A Bird New to Great Britain}

AN interesting addition to the British bird list is described by H. F. Witherby in the March issue of British Birds, namely, the first identified specimen of the western little bustard (Otis tetrax tetrax). This specimen was one of two "strange birds" shot during a partridge drive at the Wadworth estate of Yorkshire, just south of Doncaster, so far back as December 9 , 1922. The shooting tenant presented the specimen to Capt. E. W. S. Foljambe, who had it preserved at Osberton, Nottingham, whence he recently sent it to London for expert study. The whereabouts of the second bird shot on that date have not been traced. The western race of the little bustard inhabits Spain, Portugal, France and north-west Africa, and differs from the eastern race in the possession of more sandy-buff colour on the upper parts and wing-coverts, in having the black markings less pronounced, and the vermiculations finer. The eastern little bustard (Otis tetrax orientalis) had previously been recorded in Great Britain, and the specimen was at first thought to belong to that race. One was shot at Addlethorpe, Lincolnshire, in November 1933, another in Kincardineshire in 1912, one near Peterhead, Aberdeenshire, in January 1935 and one in Hampshire during a partridge drive in December 1935.

\section{Journal of the Glasgow Mathematical Association}

WE have only just received the first two numbers of this journal, although the first appeared so long ago as December 1936, and the second a year later. The Glasgow Mathematical Association is the successor to the "Euclidean Society" formed in Glasgow in 1927. Its objects form a curious contrast with those of the well-known Mathematical Association, which is the successor to "The Association for the Improvement of Geometrical Teaching". The objects of the latter might be described as revolutionary, in the first place to break away from the shackles of Euclid, and then to break away also from the traditional methods of teaching algebra, trigonometry and other branches of elementary mathematics. The Glasgow Association, on the other hand, is counter-revolutionary. Its original object was to adhere to Euclid's methods whenever the substitutes were considered unsatisfactory. An article by J. McWhan pleads also for a return to the "uninspiring but fundamental topics" in algebra and trigonometry, and claims that "the drill itself, and the concentration and self-discipline implied in it, are surely of the highest educational value", although "not in itself stimulating or pleasurable either to pupil or teacher". These views are supported by evidence as to the bad effects of modern methods of teaching.

THE Journal may be warmly recommended even to those teachers who do not consider that what is pleasant is probably evil. There are interesting historical articles on Stirling and Monge, and a most valuable exposition of the "Intuitionist" point of view concerning the nature of mathematics. This, if accepted, would necessitate a drastic pruning and remodelling of the whole of abstract function theory, such as the Heine-Borel theorem, and would reject the theory of non-enumerable classes and Lebesgue measure as merely "verbal mirages". There is also an article on compass constructions, and notes on the teaching of geometrical progressions, medial section, the construction of triangles, the sums of powers of the natural numbers, and the binomial theorem.

\section{Plague Research in India}

IN the report of the Haffkine Institute, Bombay, recently issued, the Director, Lieut.-Colonel Sokhey, summarizes the work of the Institute during 1936. It is the centre for the manufacture of plague vaccine for the whole of India, and more than 800,000 doses of vaccine were issued during the year. Much work has been done on the standardization of the dose of virulent plague bacilli for measuring the protective power of plague vaccines, and upon the preparation of a potent anti-plague serum for treatment. Investigations on the epidemiology of plague have shown that the house rat in some localities is resistant to plague, but that in them the small field rat is highly susceptible, and is probably responsible there for the spread of the disease.

\section{The Night-Sky in May}

The moon is full on May $14^{\mathrm{d}}$ at $8 \cdot 6^{\mathrm{h}}$ and new on May $29^{d}$ at $14 \cdot 0^{\mathrm{h}}$ U.T. At full moon, a total eclipse of the moon occurs, but this is invisible from Europe. At new moon on May 29, a total eclipse of the sun takes place, but this phenomenon is likewise invisible from Europe, the path of totality lying in the southern part of the South Atlantic Ocean. The sun will be seen partially eclipsed from South Africa and the southern part of South America. Amongst the occultations visible from Greenwich this month may be noted the following: on May 2 at $20^{\mathrm{h}} 5 \cdot 1^{\mathrm{m}}$ the disappearance of 106 Tauri (mag. 5.3); on May 3 at $20^{\mathrm{h}} 41 \cdot 8^{\mathrm{m}}$ the disappearance of 68 Orionis (mag. $5 \cdot 7)$; on May 12 at $20^{\mathrm{h}} 57 \cdot 2^{\mathrm{m}}$ the disappearance of B.D. $-15^{\circ} 3817$ (mag. 5.1) and on May 17 at $1^{\mathrm{h}} 39 \cdot 0^{\mathrm{m}}$ the reappearance of 58 Ophuichi (mag. 4.9). Of planetary phenomena to be looked for is the unusually close approach of Venus and Mars on the evening of May 7, the actual conjunction taking place on May $8^{\mathrm{d}} 0^{\mathrm{h}}$, that is, about $2 \frac{1}{6}$ hours after the planets have set below the horizon at Greenwich. Binoculars should be used to see this interesting phenomenon, and the difference in colour of the two planets will be observed. On May $1^{\mathrm{d}} 19^{\mathrm{h}}$ and May $31^{\mathrm{d}} 16^{\mathrm{h}}$, Venus is in conjunction with the moon; on May $2^{\mathrm{d}} 1^{\mathrm{h}}$ and May $30^{d} 18^{h}$, Mars is in conjunction. Jupiter, a morning star, is in conjunction with the moon on May $22^{\mathrm{d}} 17^{\mathrm{h}}$. In the middle of the month at $21^{\mathrm{h}}$ a very interesting region of the sky is on the meridian. This region contains an assembly of nebulæ in Virgo and Coma Berenices and the loose cluster of bright stars that form the mythical tress of hair of Berenice. East of this cluster is the north galactic pole, in the direction of which the 100-inch telescope has explored the remote extra-galactic nebulæ to a distance of more than 500 million light years. Hubble states 